\title{
RING CURRENT ENERGY INPUT AND DECAY
}

\author{
JANET U. KOZYRA and MICHAEL W. LIEMOHN \\ Space Physics Research Laboratory, University of Michigan, Ann Arbor
}

\begin{abstract}
A new view of the ring current as an active element in the geospace system has emerged in which the ring current responds not only to changing convection electric fields imposed by solar wind interactions but to internal dynamics of the magnetosphere-ionosphere-atmosphere (geospace) system. Variations in the plasma sheet density, temperature and composition, saturation of the polar cap potential drop (and presumably the cross-tail potential drop), modifications to the imposed convection potential in the inner magnetosphere due to ring current shielding effects, the presence of a pre-existing ring current population, storm-substorm coupling, and strong convection with and without accompanying substorm activity all have an impact on the ring current strength, formation and loss. All of these internal processes imply that the geoeffectiveness of a solar wind driver cannot be predicted on the basis of the characteristics of the driver alone but must reflect key aspects of the dynamically changing geospace environment, itself. This review gives a summary of new information on ring current input and decay processes focusing on implications for the global geospace response to solar wind drivers during magnetic storms and on open questions that can be addressed with new ENA imaging techniques.
\end{abstract}

Keywords: inner magnetosphere, ring current, space storms, substorms

\section{Introduction}

A geomagnetic storm occurs when merging of the interplanetary magnetic field with the Earth's magnetic field causes deep and intense circulation of the magnetospheric plasma, building up the energy content of the ring current to unusually high levels (e.g., Tsurutani and Gonzalez, 1997). The presence of a strong ring current is a defining feature of magnetic storms (c.f., Gonzalez et al., 1994). In fact, it is common practice to use the $D s t$ index as a measure of the magnetic storm intensity. The Dst (disturbance storm time) index, which is a globally-averaged axial magnetic perturbation value (Sugiura and Kamei, 1991), is measured at the surface of the Earth (low and mid latitudes) and contains contributions from the magnetopause current, the partial and symmetric ring currents, the substorm current wedge, the magnetotail currents, and induced currents in the diamagnetic earth. $D s t^{*}$, the global perturbation from near-Earth currents, is obtained by correcting the Dst index for magnetopause current contributions and for induced currents in the solid earth. A number of recent studies using in situ satellite data have presented observational tests showing that the ring current contribution (partial and symmetric) dominates the $D s t^{*}$ index (e.g., Greenspan and Hamilton, 2000), while other current systems are estimated to contribute only a few tens of $\mathrm{nT}$ at 
most (e.g., Carovillano and Siscoe, 1973; Crooker and Siscoe, 1974; Turner et al., 2000). Considerable uncertainty still exists over the non-ring current contributions to $D s t^{*}$ which some models predict to be substantial (Alexeev et al., 1996). ENA emissions, which are largely unaffected by these other current systems, are a more direct measure of the ring current energy content. For a number of magnetic storms, Jorgensen et al. (1997; 2001) report a good correspondence between ENA observations of the total ring current energy and $D s t$ lending strong support to the use of $D s t^{*}$ as a monitor of ring current growth and decay.

It is generally accepted that the ring current is formed partially from ions with direct convective access to low $\mathrm{L}$ values and partially from higher energy ions on closed drift paths diffusing in under the influence of fluctuating electric and magnetic fields (Lyons and Schulz, 1989). Chen et al. (1994) showed that the energy demarcating these two populations for large storms at $L=3$ is $\sim 160 \mathrm{keV}$. Since ions in the energy range 10-200 $\mathrm{keV}$ are responsible for the majority of the ring current energy content (and thus $D s t^{*}$ variation), most of the ring current forms through convective transport from the inner plasma sheet. A strong correlation between geosynchronous plasma sheet density at midnight and minimum $D s t^{*}$ (Thomsen et al., 1998) supports this viewpoint. Further, Nose et al. (2001) infer that the plasma sheet is the dominant source for the ring current based on the similarity in composition of the inner plasma sheet and outer ring current regions.

Given a relatively long main phase, plasma sheet ions moving on open drift paths into the inner magnetosphere are not captured on closed drift paths but move through to the dayside magnetopause and are lost. During such events, the ring current is highly asymmetric (e.g., Takahashi et al., 1990) with up to $90 \%$ of the energy flowing along open drift paths in the main phase (Liemohn et al., 2001a; Kozyra et al., 2002). In situ measurements are consistent with this asymmetry (e.g., Frank, 1970; de Michelis et al., 1997; Grafe, 1999). One of the first great successes of energetic neutral atom (ENA) imaging was experimental confirmation of this asymmetry (Roelof, 1987; Henderson et al., 1997; Pollock et al., 2001; Mitchell et al., 2001; Reeves and Spence, 2001). In fact, the images in Mitchell et al. (2001) capture the dramatic conversion of open to closed drift paths (asymmetric to symmetric ring current) during a step-like transition to northward $\mathrm{Bz}$ in the main phase of a large magnetic storm. Energetic (tens of $\mathrm{keV}$ ) $\mathrm{O}^{+}$has been observed in front of the bow shock (seen out to $200 R_{E}$ upstream) during storm events (Christon et al., 2000; Posner et al., 2002), indicating that the ring current is flowing out the dayside magnetopause at these times. The upper atmosphere also provides evidence for a partial ring current during storms, with Craven et al. (1982) (and references therein) showing that stable auroral red (SAR) arcs are primarily limited to the dusk-to-midnight sector. In their review of SAR arcs, Kozyra et al. (1997a) concluded that the Coulomb interaction between the thermal electrons and the ring current is responsible for the magnetospheric heat flux that produces SAR arcs. From simulations, Liemohn et al. (2000) showed that the local time asymmetry of the partial ring current matches the SAR arc observations. 
There are two primary drivers for the stormtime ring current: the plasma source strength and the convective drift strength. The plasma sheet is an essential participant in magnetic storm dynamics as a reservoir of ring current particles. Depending on the solar wind driving, the plasma sheet can become superdense (up to $10 \mathrm{~cm}^{-3}$ ) (Borovsky et al., 1997), heated (temperatures of $>10 \mathrm{keV}$ in the nearEarth region, rather than 5-8 keV), and enriched in ionospheric ions (Young et al., 1982; Moore and Delcourt, 1995; Fu et al., 2001). The energy density in the plasma sheet, in general, is higher during magnetic storms than quiet times (e.g., Nose et al., 2001) but, it is also highly variable, modulating the relative geoeffectiveness of comparable southward IMF intervals even within a single magnetic storm (Liemohn et al., 2001a; Kozyra et al., 2002). Unusual populations are sometimes seen, such as plasma with characteristics resembling low latitude boundary layer (LLBL) plasma moving along open drift paths into the inner magnetosphere near midnight (Kozyra et al., 1998a).

The convection within the magnetosphere is driven by interaction with the solar wind. During periods of southward interplanetary magnetic field (IMF), reconnection on the dayside sweeps magnetic flux to the magnetotail, creating a pressure gradient that drives plasma back toward the sun. This convection strength has been correlated to the solar wind motional electric field (Ey) and the electric potential difference across the high latitude ionosphere (e.g., Reiff et al., 1981). Several studies have correlated Ey with $D s t^{*}$ decreases (Burton et al., 1975; Akasofu, 1981), and O'Brien and McPherron (2000) demonstrated an additional correlation between Ey and $D s t^{*}$ recovery.

This is consistent with the fact that ion flowout through the dayside magnetopause has been shown by kinetic ring current models (Takahashi et al., 1990; Ebihara and Ejiri, 1998; Liemohn et al., 1999) to be the major ring current loss process during the main phase of intense magnetic storms. The time scale for ion loss due to these drifts is proportional to the convection electric field and thus to the interplanetary eastward electric field. A direct measurement confirming the difference in character between globally-averaged main and recovery phase ring current losses during a major magnetic storm was provided using ENA observations by the Polar spacecraft (Jorgensen et al., 2001). Loss rates during the late recovery phase were consistent with charge exchange as the loss mechanism; however, during the main phase, losses were well in excess of charge exchange losses. Though this was not addressed in the study, it is almost certain that Polar was viewing the transition between flow-out losses and charge-exchange losses as the primary cause of $D s t^{*}$ variation.

With the demonstrated power of ENA imaging to provide a global perspective and separate spatial versus temporal variations, it is an excellent time to review present knowledge of ring current source and loss processes from models and observations and identify areas where major questions remain. To investigate the interplay between plasma sheet dynamics and convection in driving the storm-time ring current, the results of kinetic simulations of 8 magnetic storms are examined. 
The next section describes the computational approach to these simulations, followed by a section introducing the selected events and showing globally-integrated theory-data comparisons. Using the simulation results and observations in the literature, the next two sections examine the sources and losses, respectively, of the stormtime ring current. This is followed by a discussion of major outstanding issues.

\section{Modeling Technique}

In order to examine the relative roles of the various source and loss processes in ring current dynamics, a numerical simulation tool will be employed. The code to be used for this analysis is the same one used by Liemohn et al. (1999, 2001a), based on one originally developed by Fok et al. (1993) and Jordanova et al. (1996) at the University of Michigan. This Ring current-Atmosphere interaction Model (RAM) solves the time-dependent, gyration- and bounce-averaged kinetic equation for the phase-space distribution function $f\left(t, R, \varphi, E, \mu_{0}\right)$ of a chosen ring current species. The five independent variables are time $t$, geocentric distance in the equatorial plane $R$, magnetic local time $\varphi$, kinetic energy $E$, and cosine of the equatorial pitch angle $\mu_{0}$. The code includes collisionless drifts, energy loss and pitch angle scattering due to Coulomb collisions with the thermal plasma, charge exchange loss with the hydrogen geocorona, and precipitative loss to the upper atmosphere (this term is limited to pitch angles that map to the upper atmosphere, $\left.\mu_{0, L C} \leq \mu_{0} \leq 1\right)$. The numerical grid consists of a few thousand velocity space cells at each of a few hundred spatial locations, for a total of $\sim 1.4$ million phase space cells (for each ring current ion species). For these simulations, the major ring current species of $\mathrm{H}^{+}$and $\mathrm{O}^{+}$are computed. Note that this is not a particle-tracking code but actually a several-thousand-fluid calculation (the 'fluids' being the grid cells in velocity-space). Please see Fok et al. (1993), Jordanova et al. (1996), and Liemohn et al. (2001a) for further details of the computational technique.

For the purposes of creating a boundary condition for the ring current simulation, geosynchronous orbit (the outer extent of the simulation domain) is assumed to be inside of the substorm injection boundary (that is, convection alone moves the particles into the simulation domain). Observations are taken from the magnetospheric plasma analyzer (MPA) (Bame et al., 1993) and synchronously orbiting plasma analyzer (SOPA) (Belian et al., 1992) instruments on the satellites operated by Los Alamos National Laboratory (LANL). Variations in the observed plasma sheet density are taken to represent temporal variations of a spatially uniform nightside plasma sheet (see Liemohn et al. (1999) for details of this method). The composition of the MPA density or flux $\left(n_{b}\right.$ or $\phi_{b}$ ) of species $\alpha$ is assumed to vary with solar and magnetic activity according to the statistical relationship derived by Young et al. (1982) while the SOPA data is assumed to be mostly $\mathrm{H}^{+}$(with kappa 
function high-energy tails for the other species through the SOPA energy range; note that these kappa tails are invariably much lower than the SOPA observations).

The kinetic model is linked with other models to specify the background conditions during the simulations. The most critical of these is cross polar cap potential, used to scale the strength of the convection potential, which is obtained from the assimilative mapping of ionospheric electrodynamics (AMIE) technique (Richmond and Kamide, 1988). These potentials are then used to drive a modified McIlwain E5D electric field model (derived from inner magnetospheric particle drifts) (McIlwain, 1986), along with the Air Force Research Laboratory midnight auroral boundary index (Gussenhoven et al., 1983) for the shielding parameter (see Liemohn et al., 2001a). In addition, RAM uses the Rairden et al. (1986) geocorona description, which provides the neutral particle description for the charge exchange interaction, and the Rasmussen et al. (1993) dynamic plasmasphere model, which provides core plasma densities for the Coulomb collision interactions. RAM presently uses a dipole magnetic field. While the self-field will inflate the inner magnetosphere, pushing the particles out and decreasing their influence on Dst the lower magnetic field will increase the azimuthal current density from these particles, so the net influence of a more realistic magnetic field is unclear. Also, while substorms are not explicitly taken into account in the model, both the plasma boundary condition and AMIE potential will be affected by substorms, so they are indirectly included in the simulations. Note that the observed $D s t$ or $D s t^{*}$ values are not used as inputs to the model nor are upstream solar wind quantities used to drive the model.

\section{Eight Magnetic Storms}

In the following sections, the energy input and output from the ring current is considered for eight magnetic storms: June 4-7, 1991; May 14-17, 1997; September 24-27, 1998; October 18-21, 1998; October 21-24, 1999; April 6-9, 2000; May 23-26, 2000; and July 14-17, 2000. These events span an entire solar cycle and are quite diverse in their solar wind and geophysical conditions. The motional electric field in the solar wind is plotted for all of the magnetic storms in the top panel and the observed Dst (black line), observed $D s t^{*}$ (red line) and modeled $D s t^{*}$ (blue line) in the second panel of Figures 1-8.

As mentioned above, the $D s t^{*}$ index is a measure of the magnetic perturbation from near-Earth current systems. It is derived from Dst according to (c.f. McPherron, 1997; Kozyra et al., 1998a)

$$
D s t^{*}=\frac{D s t-D_{M P}+D_{Q R C}}{C_{I C}}
$$

In (1), $C_{I C}$ is the correction due to induced currents in the Earth, taken to be 1.3 (Dessler and Parker, 1959; Langel and Estes, 1985); $D_{M P}$ is the perturbation from 
the Chapman-Ferraro currents on the magnetopause, taken to be $15.5 \sqrt{P_{s w}}$ (solar wind dynamic pressure in $\mathrm{nPa}$ ) (Burton et al., 1975; Gonzalez et al., 1994), and $D_{Q R C}$ is the contribution from the quiet time ring current (subtracted out as a baseline offset of $D s t$ ), taken to be $-20 \mathrm{nT}$ (Burton et al., 1975). The second panel of Figures 1-8 shows Dst (solid lines) and $D s t^{*}$ (dotted lines) for the 8 selected storms. All of the events have a storm sudden commencement (SSC) followed by a rapid drop of 100-300 nT. Note that there is a significant difference between Dst and $D s t^{*}$ during the main phase of the storms, particularly around the SSCs. $D s t^{*}$ is often $50 \mathrm{nT}$ below Dst. This is because the magnetopause contribution to Dst is largest at these times (coincident with the pressure enhancement at the leading edge of the interplanetary shock). Often, $D s t^{*}$ starts to decrease as soon as the SSC begins. This is because the near-Earth current systems are rapidly responding to the disturbance. For the ring current, this means expelling the preexisting trapped population and starting to bring in fresh plasma sheet ions into the inner magnetosphere.

The simulation results from the model described above can be condensed down to a single number: a modeled $D s t^{*}$. This is done by using the Dessler-ParkerSckopke relation (Dessler and Parker, 1959; Sckopke, 1966),

$$
D s t_{D P S}^{*}[n T]=3.98 \cdot 10^{-30} E_{R C}[n T]
$$

which linearly equates the magnetic perturbation at the center of the Earth (a proxy for the globally-averaged perturbation) with the total ion energy content in the dipole magnetic field. The derivation of (2) is for an arbitrarily-distributed plasma (in both real space and velocity space) in a dipole magnetic field, and it only takes into consideration the cross-magnetic-field currents in the magnetosphere (see the discussion by Carovillano and Siscoe (1973)). If this current is spatially (azimuthally) asymmetric, then there will be field-aligned and ionospheric closure currents to complete the circuit that are not accounted for in (2). However, the strong statistical correlation between ring current energy (estimated from in situ satellite observations) and Dst (Greenspan and Hamilton, 2000) implies that the contributions from other current systems and the ring current self-field are either small or cancel each other out on average. In fact, total ENA emissions (which are independent of these other current systems) show a good correspondence with Dst for a number of magnetic storms (Jorgensen et al., 1997; 2001). Because of this, in the following discussion the two terms ' $D s t^{*}$ ' and 'ring current energy' will be used interchangeably.

One commonality among the eight magnetic storms is that they were all instigated by the impact of strongly southward interplanetary magnetic fields $\left(B_{z, I M F}<\right.$ $-10 \mathrm{nT}$ ) rapidly flowing past the Earth (Vsw $>600 \mathrm{~km} \mathrm{~s}^{-1}$ ). The maximum solar wind Ey for all but one of these events ranged between $10 \mathrm{mV} / \mathrm{m}$ and $20 \mathrm{mV} / \mathrm{m}$. The exception was the July 2000 magnetic storm where Ey values reached 60 $\mathrm{mV} / \mathrm{m}$ (Figure 8). The solar disturbances that triggered the May 1997 (Figure 2), September 1998 (Figure 3) and October 1998 (Figure 4) magnetic storms had two 


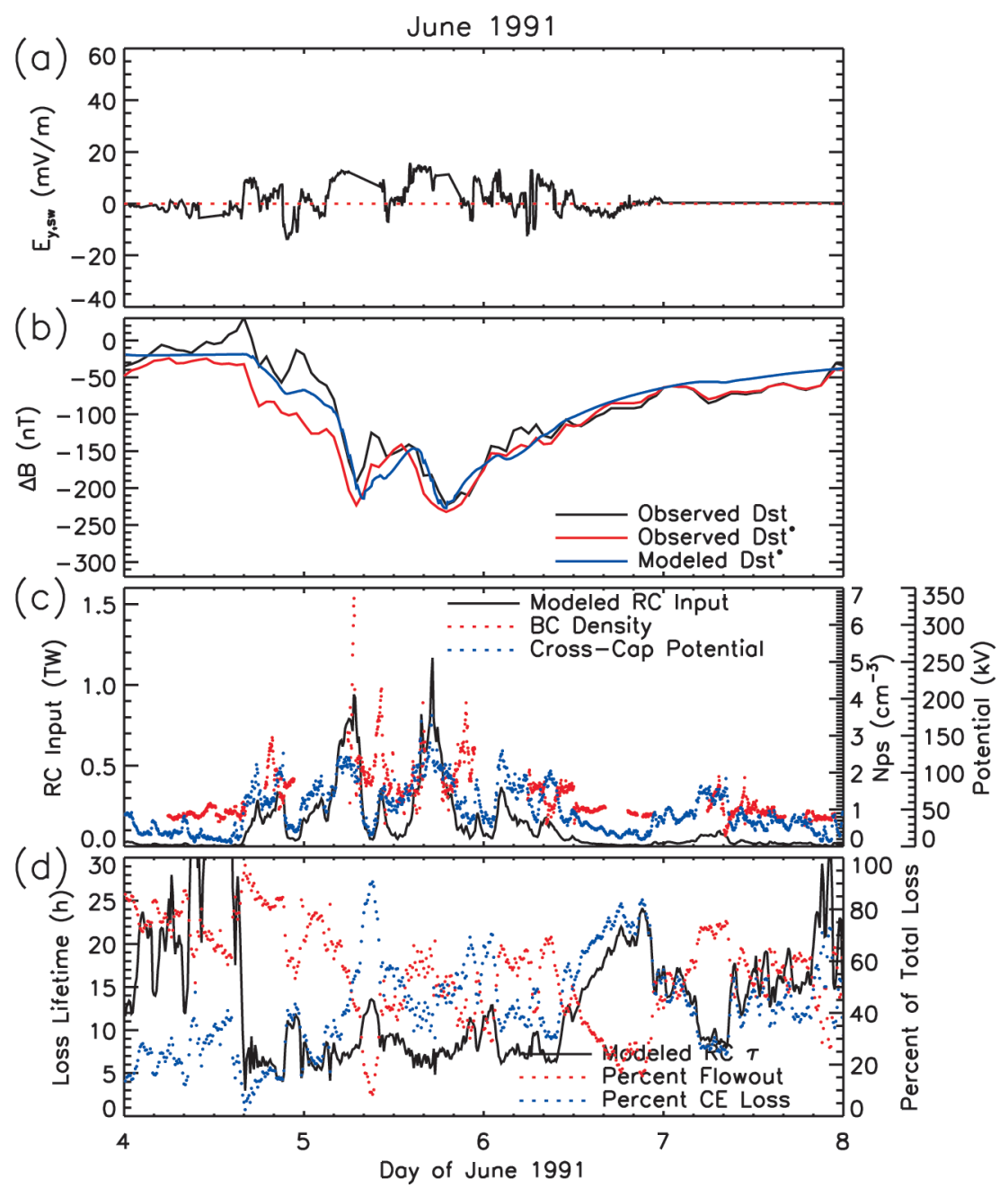

Figure 1. Simulation results for the 4-7 June 1991 magnetic storm. The solar wind Ey that triggered the storm is shown in the top panel. The modeled $D s t^{*}$ (blue line) is compared to the observed $D s t$ (black line) and observed $D s t^{*}$ (red line) in the second panel. The energy input through the nightside outer boundary ( $L=6.75$ ) of the model is plotted in the third panel (black line). This energy influx is constructed from observations of the plasma density at geosynchronous orbit (red dots) flowing inward with $\mathrm{E} \times \mathrm{B}$ velocity which is a function of the cross polar cap potential, $\Delta \Phi_{P C}$ (blue dots). The globally-average loss lifetime for the ring current is plotted in the bottom panel (black line) along with percentage of loss due to charge exchange (blue dots) and flow-out (red dots). 


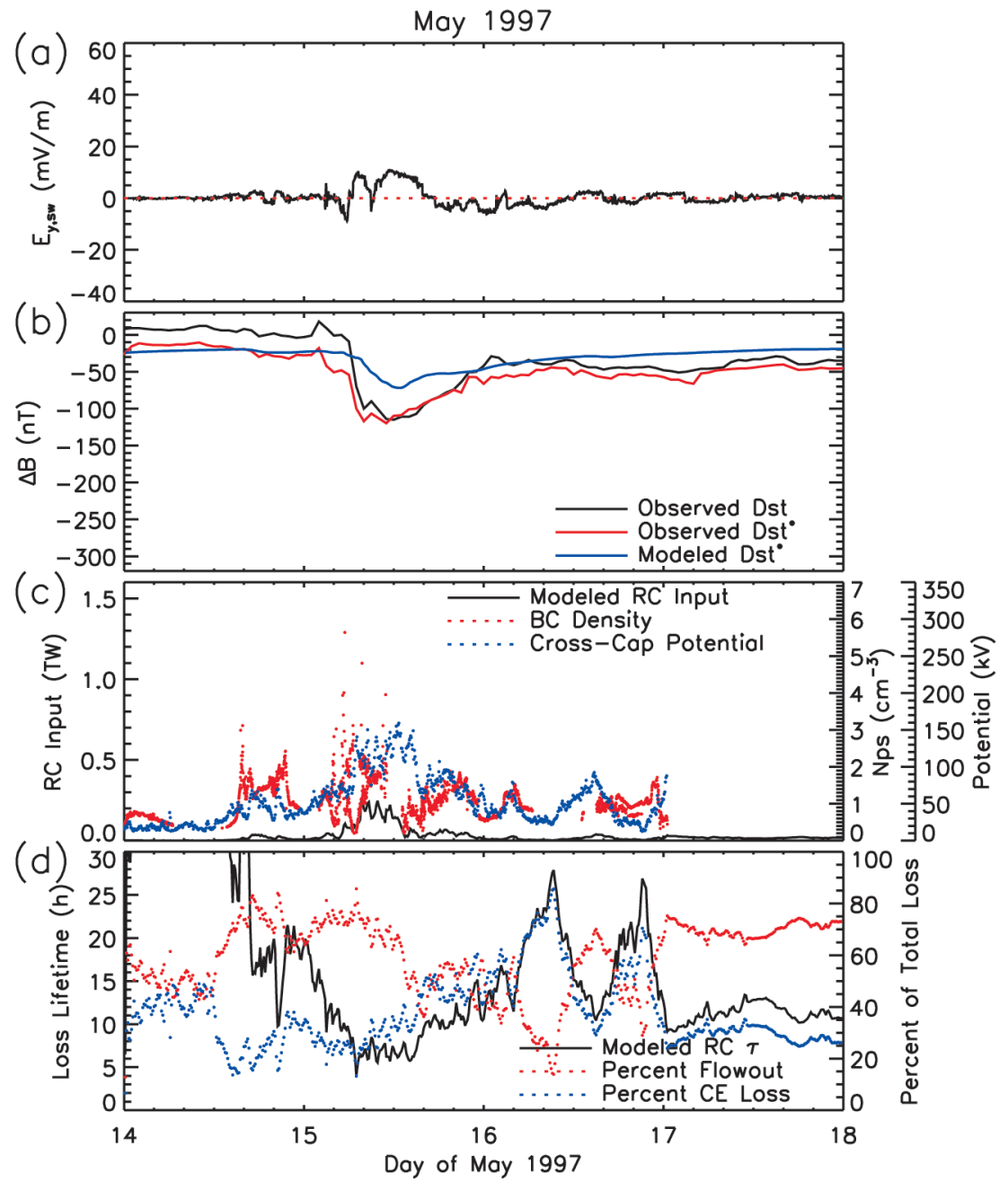

Figure 2. Simulation results for the 14-17 May 1997 magnetic storm in the same format as Figure 1.

geoeffective elements, a sheath and a magnetic cloud. The first was due to a sheath of shocked solar wind plasma driven ahead of the interplanetary coronal mass ejection (ICME) and the second due to the southward IMF Bz of the ICME itself which slowly rotated northward (Ey slowly transitioned from positive to negative values) over more than a 12 hour period. All of these storms exhibited a twophase decay. In contrast, the solar wind disturbances that drove the October 1999 (Figure 5), April 2000 (Figure 6), May 2000 (Figure 7) and July 2000 (Figure 8) magnetic storms exhibited step-like transitions from southward to northward IMF $\mathrm{Bz}$ (positive to negative Ey). In these cases, the recovery occurred in a single phase typified by a slow smooth increase in loss lifetimes. The reasons for this will be discussed below. Most of these storms have been chosen for coordinated study 


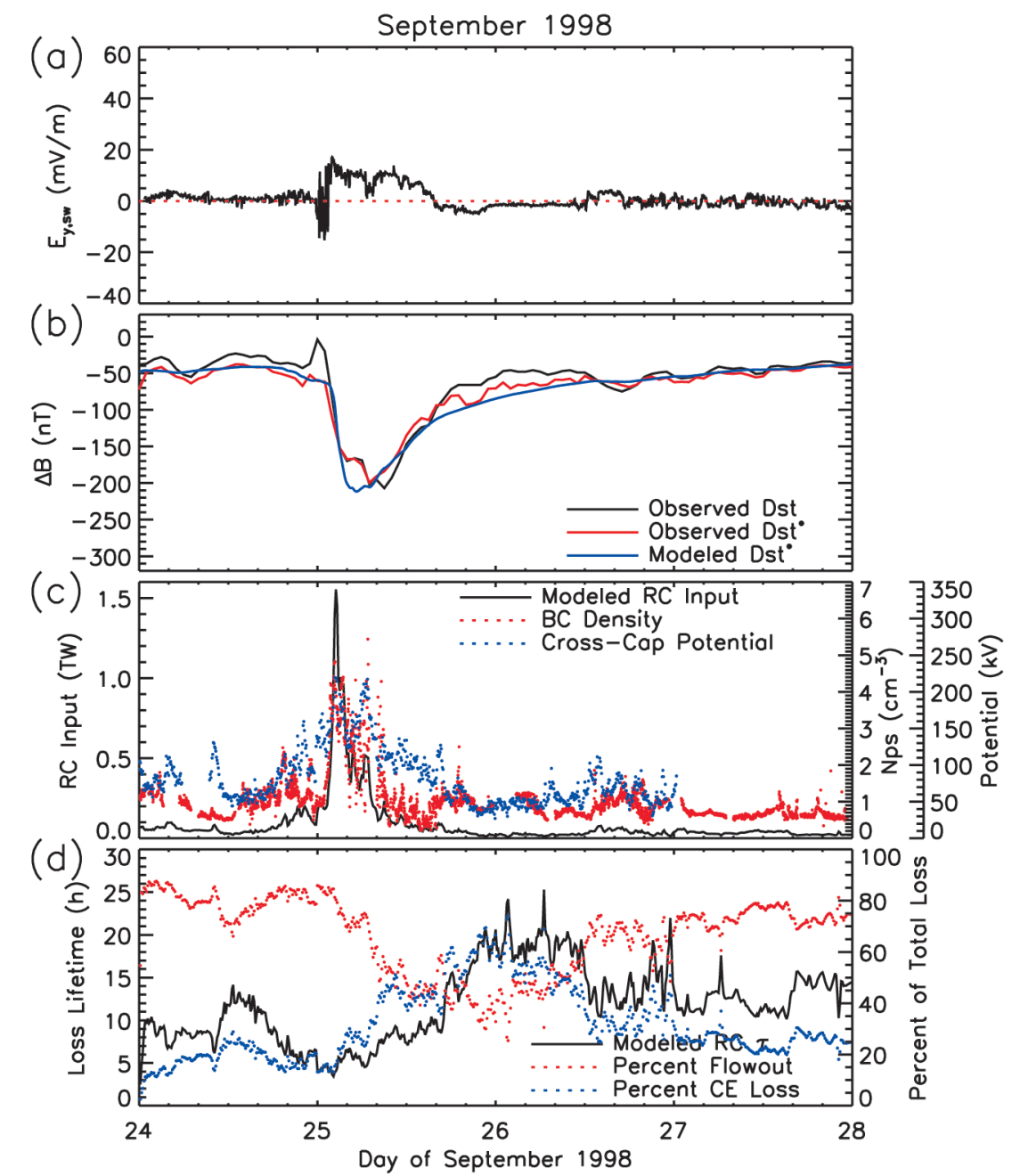

Figure 3. Simulation results for the 24-27 September 1998 magnetic storm in the same format as Figure 1.

by one or more communities, and they comprise a representative cross section of large non-recurrent magnetic storms over the last decade. The April 2000 and July 2000 events are classified as superstorms ( Dst $<-250 \mathrm{nT}$ ). Though these storms produce ring currents of comparable intensity, the solar wind drivers are vastly different. Furthermore, the solar wind Ey values are comparable for the October 1999 and April 2000 events yet the ring currents driven by these disturbances have min $D s t^{*}$ values of approximately $-240 \mathrm{nT}$ and $-320 \mathrm{nT}$, respectively. This clearly raises interesting questions related to predicting the geoeffectiveness of solar wind disturbances. 


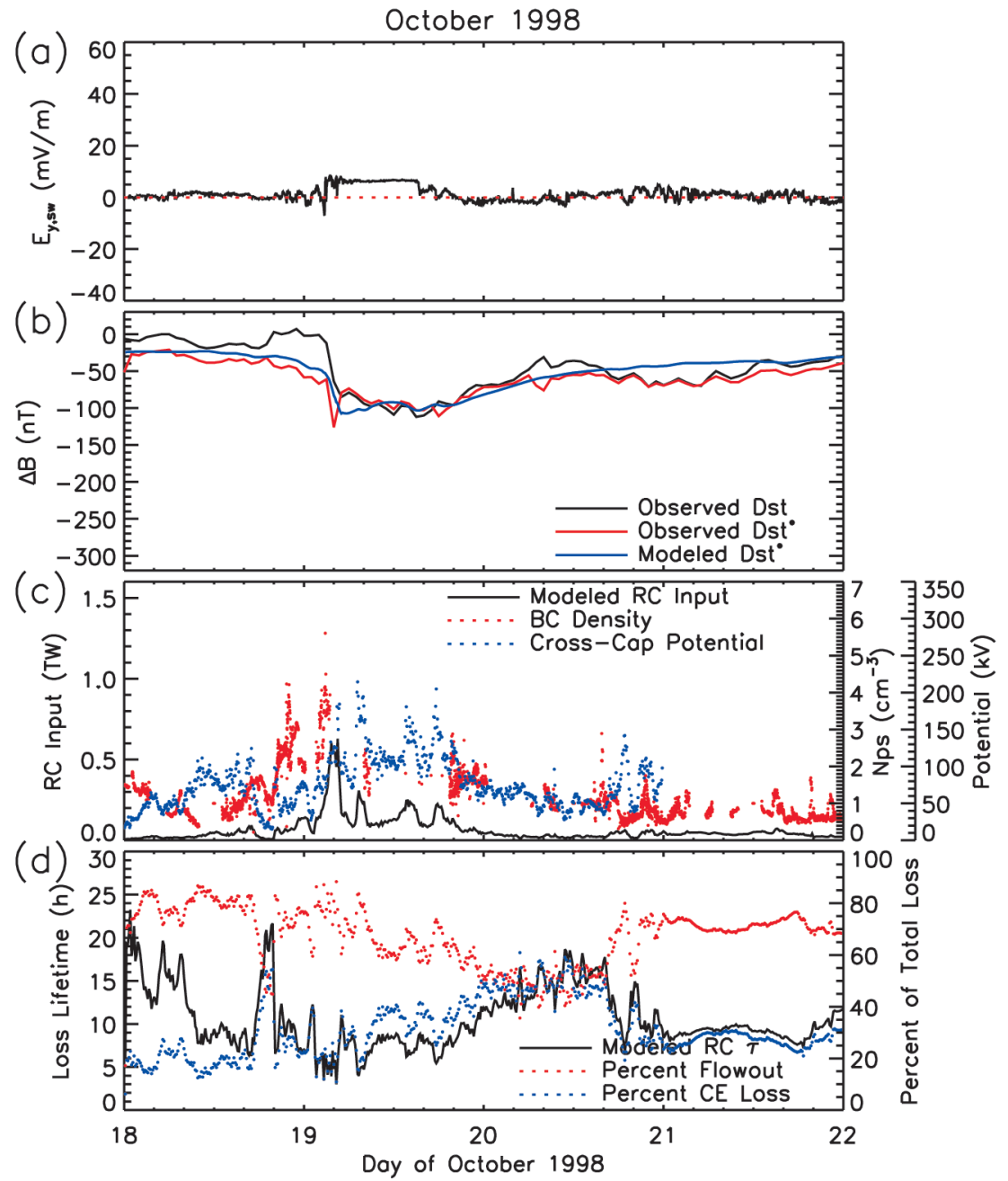

Figure 4. Simulation results for the 18-21 October 1998 magnetic storm in the same format as Figure 1.

Of the eight storm events, seven are single-dip storms, meaning that there is only one significant perturbation minimum. June 1991 is the notable exception, with three separate $D s t^{*}$ minima (Figure 1), and is a more general case of the two-stage magnetic storm development described in Kamide et al. (1998a). This preconditioning of the ring current development for this storm was discussed by Kozyra et al. (2002), finding that the strong convection of each new stage cleared out most of the ions from the previous injections. This is consistent with the Chen et al. (2000) study, which found that single- and double-dip storms with comparable energy inputs produce similarly sized ring currents. The storm in July 2000 also has an unusual time sequence, with a small storm the day before the ICME 


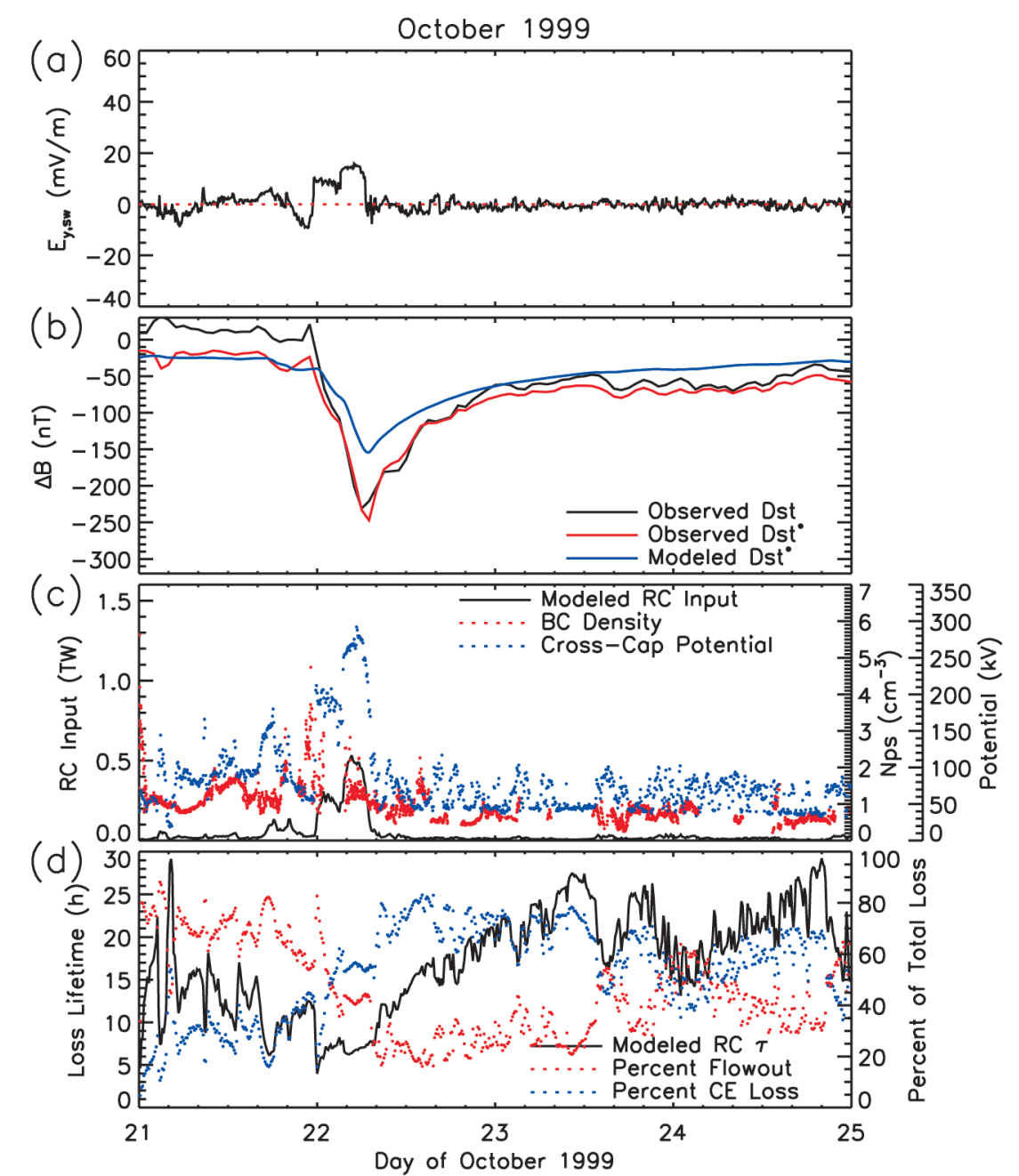

Figure 5. Simulation results for the 21-24 October 1999 magnetic storm in the same format as Figure 1.

reached Earth (Figure 8). The peak of the storms vary in duration, with $D s t^{*}$ hovering near its minimum value for some events (notably May 1997 (Figure 2) and October 1998 (Figure 4)), while other times there is a sharp transition from $D s t^{*}$ growth to recovery.

For most of the events, the model is quite good at reproducing the observed perturbation time sequence. The two most egregious exceptions to this are May 1997 (Figure 2) and October 1999 (Figure 5), where the model underpredicted the observed ring current energy by $48 \mathrm{nT}$ and $93 \mathrm{nT}$, respectively (that is, simulating only $60 \%$ and $62 \%$ of the observed $D s t^{*}$ minimum, respectively). For the April 2000 storm (Figure 6), the modeled ring current developed a couple of hours later 


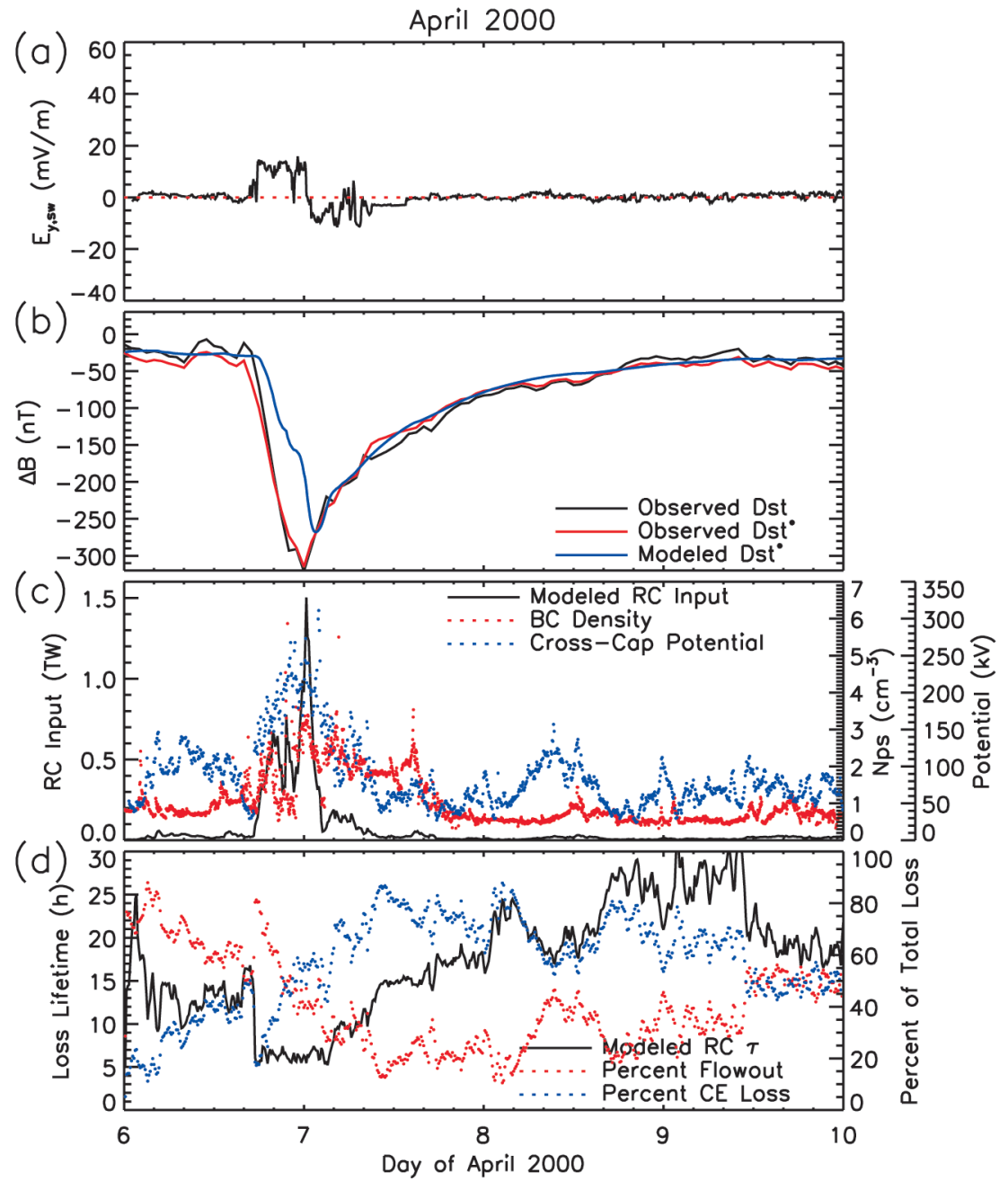

Figure 6. Simulation results for the 6-9 April 2000 magnetic storm in the same format as Figure 1.

than the observed increase, and consequently came up short by nearly $50 \mathrm{nT}$ (simulating $85 \%$ of the observed $D s t^{*}$ minimum). For the other 5 storms, the modeled $D s t^{*}$ minima are within $20 \mathrm{nT}$ of the observed minima. In all cases, the overall shape of the observed and modeled $D s t^{*}$ curves are quite similar. Inconsistencies are most likely due to inaccuracies in the computational technique (most notably from incorrect driver parameters), or because of the contributions to $D s t^{*}$ from other near-Earth current systems (besides the azimuthal component of the ring current). 


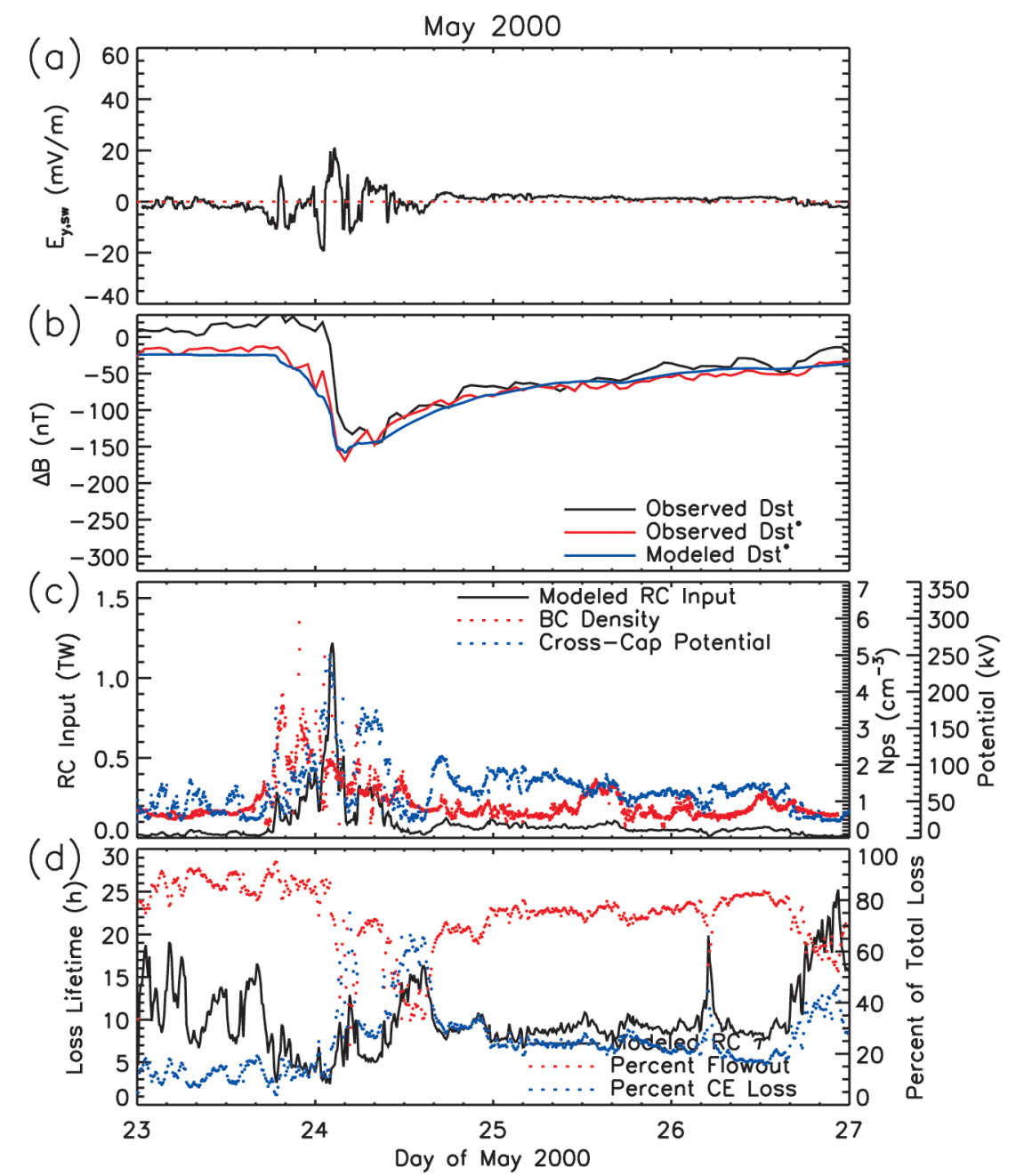

Figure 7. Simulation results for the 23-26 May 2000 magnetic storm in the same format as Figure 1.

\section{Ring Current Input}

As stated above, the two most important driving parameters for the stormtime ring current are the near-Earth plasma sheet ion characteristics and the convection electric field intensity. To begin, each of these terms is examined independently. The third panel in Figures $1-8$ shows the ring current energy input rate in the simulations for the 8 storms (solid lines) along with the corresponding plasma sheet density (maximal geosynchronous observations within 4 hours of local midnight, subsequently applied uniformly across the nightside outer boundary (see Liemohn et al., 2001a)) used as the boundary condition in the calculations (red dots) and $\Delta \Phi_{P C}$ (blue dots) provided by the AMIE model. Note there is a time lag 


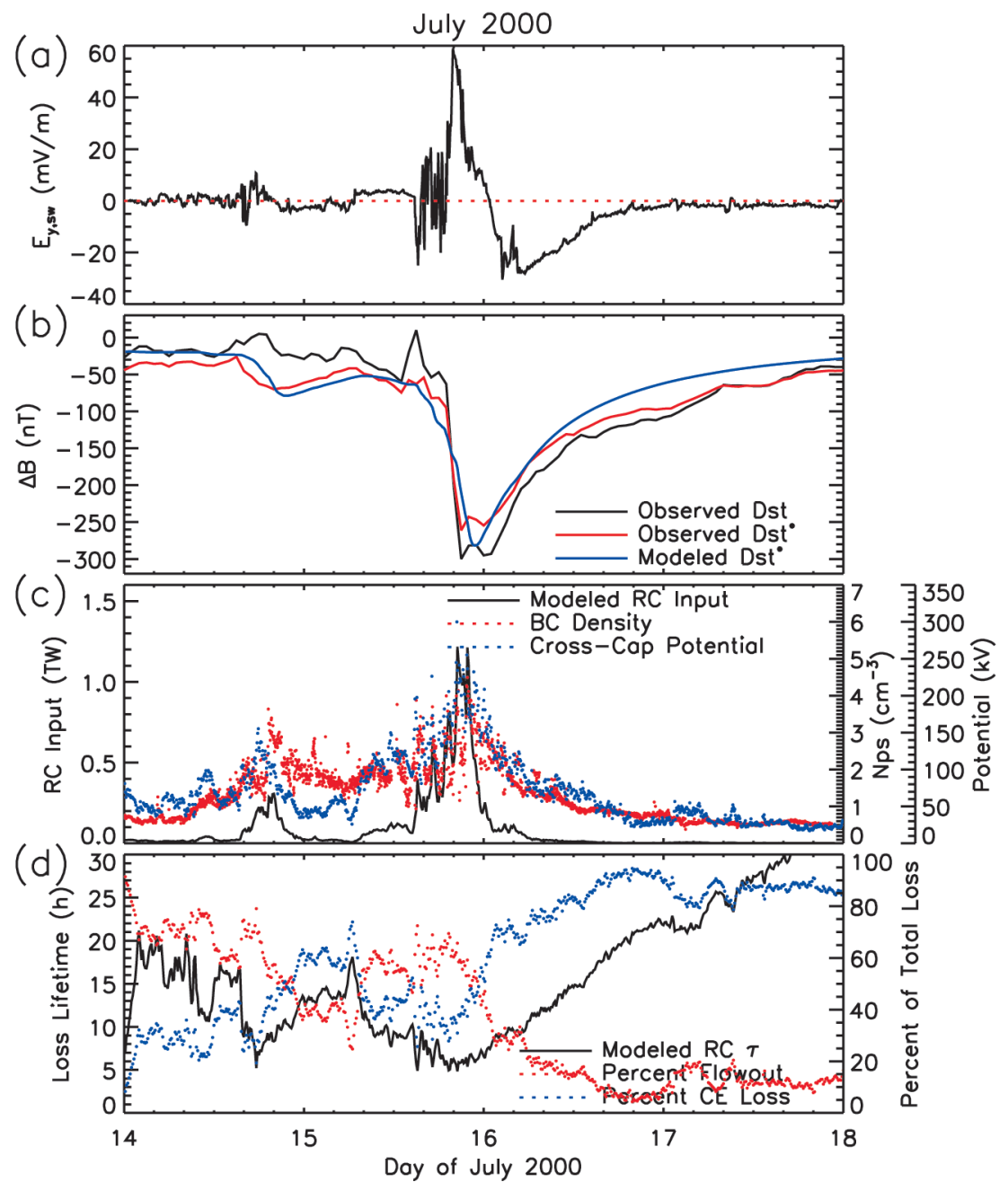

Figure 8. Simulation results for the 14-17 July 2000 magnetic storm in the same format as Figure 1.

between large values of the energy input and the $D s t^{*}$ response because it takes a few hours for the ions to convect deep into the inner magnetosphere (simulation domain) and make their maximum contribution to the total ring current energy. Sometimes significant energy input occurs during times when the total ring current energy is decreasing ( $D s t^{*}$ recovery), simply because a larger injection is being simultaneously swept out of the region.

The interplay between the strength of the convection and the density of the plasma sheet (ring current source population) controls the energy input function and thus the resulting ring current development. When the energy input rate jumps to unusually large values, it is seen that both driver parameters are elevated. There are a number of notable examples where the timing of the plasma sheet density 
variations relative to the enhanced convection fundamentally impacted the resulting ring current development. During the September 1998 magnetic storm (Figure 3) the convection (represented here by $\Delta \Phi_{P C}$ as derived by the AMIE technique and applied to the modified Mcllwain field description) remained high after the minimum $D s t^{*}$ but the plasma sheet density dropped to low values. As a result the ring current decayed rather than intensifying as the strong Ey of the ICME swept past the Earth. During the October 1999 (Figure 5) and May 2000 (Figure 7) magnetic storms, the peak in the plasma sheet density arrived just prior to the peak in the storm-time enhanced convection limiting the strength of the developing ring current. Contrast this to the April 2000 magnetic storm (Figure 6) that had a solar wind driver very similar in strength to the October 1999 and May 2000 events. The density maximum in the plasma sheet arrived at the same time as the peak in the convection $\left(\triangle \Phi_{P C}\right)$ providing a large source population for the ring current and the storm achieved superstorm status.

Numerous studies have examined the functional relationship between Ey and $\triangle \Phi_{P C}$. Burke et al. (1999) gives a good review of the history up to that year, with all of the relationships cited in that study being linear between the two quantities. However, more recent studies have shown an extension to these relationships for very large Ey values. Weimer (2001) found good correlation with $E_{y, s w} \cdot B_{I M F}^{-1 / 3}$. Siscoe et al. (2002) showed that the high-latitude field-aligned currents can perturb the dayside reconnection region and limit the size of $\Delta \Phi_{P C}$. For the particularly unusual event of July 15, 2000, Liemohn et al. (2002b) showed that a saturated $\Delta \Phi_{P C}$ is necessary to obtain reasonable agreement between data and theory for the ring current. The saturation of the polar cap potential, in effect, limits the entry of solar wind energy for extreme events. It is clear that the dynamics of the magnetosphere-ionosphere-atmosphere system have far-reaching implications for determining the geoeffectiveness of solar wind disturbances during magnetic storms.

Other factors, such as composition and temperature of the near-Earth plasma sheet and the morphology of the inner magnetospheric convection pattern, also play a critical role in determining the energy input rate to the ring current. Because of their heavier mass, oxygen ions carry more energy per unit number density than protons. The enhanced ionospheric outflow during storms (e.g., Moore et al., 1999) enriches the $\mathrm{O}^{+}$content in the plasma sheet, and this stormtime variation is clearly seen in composition measurements (e.g., Young et al., 1982; Lennartsson and Shelley, 1986; Nose et al., 2001; Fu et al., 2001; Pulkkinen et al., 2001). However, these studies show substantial scatter about the mean trends. It is hoped that global imaging of energetic neutral atoms (a by-product of the charge-exchange loss process) will reveal the true compositional distribution of the stormtime ring current.

The plasma sheet temperature can also play a role in total energy input and $D s t^{*}$ evolution. Ebihara and Ejiri (2000) conducted a parametric study of the influence of the near-Earth plasma sheet temperature on the ring current, determining that, 
for a given convection strength, there is an ideal temperature that will yield the maximum magnetic perturbation. For their computational setup, this temperature was around $5 \mathrm{keV}$. The reason for this dependence is seen by examining the ion drift terms. At very low energies, corotation dominates the flow of particles near the Earth, and the ions are pushed eastward around the planet and cannot approach close enough to create a sizable perturbation. At very high energies, gradientcurvature drift dominates the flow of particles near the Earth, and the ions are swept westward around the planet and again cannot approach very close to the Earth. At intermediate energies, these two forces balance each other enough to allow ions to have access to the inner magnetosphere. As they convect inward, they adiabatically energize, eventually drifting westward around dusk, and finally (in a steady convection field) are swept out toward the dayside magnetopause. This ideal temperature is highly-dependent on the convection strength, its time history, and its morphological pattern near the Earth.

ENA images contain new information about the distribution of the electric potentials in the inner magnetosphere, in particular about modification to these potentials due to the closure of the partial ring current through the subauroral ionosphere. Jordanova et al. $(1999 ; 2001)$ showed that the differences between convection descriptions can greatly influence the local distributions of the ring current ions, and Liemohn et al. (2001b; 2002a) showed that this also affects the bulk parameters of the ring current. Similarly, Ridley and Liemohn (2002) calculated the electric potential distribution created by the stormtime partial ring current. The main feature is a large potential well near midnight coincident with a rise in the plasma pressure. This acts to suppress the convection strength in the near-Earth plasma sheet and enhance it in the region close to the Earth (midlatitudes). Such field configurations are seen in the magnetosphere (Rowland and Wygant, 1998; Burke et al., 1998) and in the ionosphere (Yeh et al., 1991; Anderson et al., 2001). Ring current calculations that self-consistently include this potential distribution show that it slightly rotates the asymmetric ring current eastward (Garner, 2000; Fok et al., 2001).

\section{Ring Current Decay}

Because storms can last for hours or even days, ions injected on the nightside are able to drift completely through the inner magnetosphere and out to the dayside magnetopause. This drift time is highly dependent on particle energy and convection strength, but for the bulk of the ring current energy range under the influence of a strong electric field, it takes a few (2-10) hours. Therefore, flowout loss can be a significant term in the energy balance of the stormtime ring current. This is contrary to the long-held belief that charge exchange is the only significant loss process affecting the decay timescale of the ring current (e.g., Daglis et al., 1999). If the convection strength remains high but the plasma sheet density is decreasing, 
then lower density plasma will gradually replace higher density plasma on open drift paths with an overall loss of ring current energy. If the plasma sheet density remains high but the convection strength gradually diminishes, then newly entering plasma will move along open drift paths at higher radial distances with less adiabatic energization. Old plasma moving along drift paths previously connected to the magnetotail (under stronger cross-tail electric potentials) will be trapped or drift out the magnetopause depending on its location relative to the new open/closed drift shell boundary. Again this results in a net loss of ring current energy. As long as the IMF gradually rotates from southward to northward, the loss rate is a mixture of that due to decreasing plasma sheet source strength and weakening convection. However, if the transitions to northward IMF are step-like, the bulk of the ring current immediately becomes trapped and charge exchange loss dominates the decay.

By dividing the total energy content of the ring current by the total energy loss rate, a decay timescale $\tau$ can be computed. This is a 'pure-loss' timescale, in that the energy content of the ring current (and so, through (2), $D s t^{*}$ as well) would recover back towards zero with an exponential folding constant of $\tau$ assuming no further energy input to the system. This quantity is shown in the bottom panel of Figures 1-8 for the 8 storms (solid lines). It is seen that, after an initial (prestorm) period of relatively long lifetimes, $\tau$ drops dramatically during the growth phase of the storm, reaching values of 5 hours or less. During the recovery phase, $\tau$ increases back to its prestorm level, and in many cases, even higher. Throughout each storm sequence, $\tau$ exhibits a substantial amount of variation, both small-scale $(<1$ hour jumps) and large-scale (jumps of several hours or more).

To investigate the reasons for this variability, it is useful to examine the relative contributions to $\tau$ from each of the major loss processes. Also plotted in the bottom panels of Figures 1-8 is the percentage of the total energy loss rate due to ion flow through the outer boundary of the simulation (red dots) and the percentage of the total loss rate due to charge exchange (blue dots). All other loss processes (precipitation into the atmosphere, energy degradation from Coulomb interactions, net adiabatic drift energy changes) play only a minor role in these simulation results (less than $10 \%$ of the total loss) and are not displayed.

Whenever the convection strength rises (or falls), flowout loss increases (or decreases); that is, flowout is intimately tied to this parameter. Since the imbalance between the energy input on the nightside and the energy outflow on the dayside actually determines the impact on the Dst, the loss lifetimes associated with the flow-out are also a function of the time-history of the energy input rate.

Charge exchange is also related to both convection and plasma sheet density. A large incoming plasma density provides more ions for the reaction, while enhanced convection intensity drives these particles closer towards the Earth (where the neutral exospheric density is larger). However, the charge exchange reaction greatly depends on the composition and velocity distribution of the hot ions. Fok et al. (1991), in their compilation of theoretical ring current decay timescales, showed 
that the charge exchange cross section is vastly different (by orders of magnitude) between $\mathrm{H}^{+}$and $\mathrm{O}^{+}$and between low and high energies. Specifically low-energy $(E<30 \mathrm{keV}) \mathrm{H}^{+}$and high energy $(E>80 \mathrm{keV}) \mathrm{O}^{+}$at $L=3$ (inner ring current region) have loss timescales of 5-10 hours, while 100s of keV protons at $L=5$ have timescales of weeks. Because of these disparate timescales, this loss process is even more sensitive to the time-history of the source terms than flowout loss. Once the particles are trapped on closed drift trajectories, charge exchange is the primary loss mechanism, preferentially eroding the fluxes of certain species, spatial regions, and energy ranges. This gradual change in the ring current distribution slowly increases the overall decay timescale.

The largest contributor to the decay rate among the remaining terms is the adiabatic loss of energy during early recovery. Because adiabatic energy gain and loss are such large terms (see, e.g., Liemohn et al., 2002a), any imbalance between the gain and loss terms can have a significant influence on the overall energy budget of the ring current. The remaining processes contribute only a few percent to the loss rate. However, loss processes not included in these simulations may increase the decay of the ring current. For instance, a static dipole magnetic field was assumed in the simulation results presented above, but a stretched field configuration will cause some ions (especially those at high energies) to violate the first adiabatic invariant as they cross the low-field equatorial plane region (Anderson et al., 1997; Lyatsky, 1999). This will cause pitch angle isotropization and subsequent loss to the atmosphere. In addition, several studies have shown that instabilities in the ring current distribution can excite plasma waves that will scatter the ions into the loss cone (Jordanova et al., 1997, 1998; Kozyra et al., 1997b, 1998b). Thus, the model results presented here should be regarded as a lower limit on the influence of other processes in the decay of the ring current.

The bottom panels in Figures 1-8 show that the stormtime ring current has an ever-changing decay lifetime. This is because the current is carried by particles of various species, energies, pitch angles, and L values, and the loss rate depends on these three parameters. The net effect is that the stormtime ring current behaves like a summation of many smaller currents, each with its own decay lifetime (Liemohn and Kozyra, 2002). This explains the lognormal distribution of Dst that Campbell (1996) revealed. Lognormal distributions naturally occur from the superposition of many processes with disparate lifetimes. Therefore the ring current (partial and symmetric), which provides the majority of the stormtime Dst signature, can account for the lognormal shape of this index.

The set of storms presented here show two very different recovery phase behaviors. June 1991, May 1997, September 1998 and October 1998 (bottom panels of Figures 1-4) are all examples of two-phase decay. Of these, June 1991 is a complicated storm because of the complex solar wind disturbance that produced it but exhibits many of the same features as the other storms in this category. For clarity, we concentrate on the other three storms in this set. During the main phases of each of these storms, flow-out loss clearly dominates. In the early recovery phase, 
flow-out and charge exchange make comparable contributions to the decay as the IMF Bz slowly rotates northward converting open to closed drift paths, cutting off the outflow and gradually trapping the remaining particles. Charge exchange dominates in the late recovery phase after the IMF Bz has turned completely northward. However, in each of these cases, the $D s t^{*}$ remains at low values $(\sim-50 \mathrm{nT})$ following the passage of the magnetic cloud, and the solar wind Ey is slightly positive at these times. Ions drifting through the inner magnetosphere at high $L$ values are responsible for maintaining the $D s t^{*}$ values and flow-out losses again dominate.

The second type of recovery phase behavior is illustrated by the magnetic storms in October 1999, April 2000, and July 2000 (bottom panels of Figures 5-8). In all of these cases, there is a step-like transition from IMF Bz southward to northward at the trailing edge of the solar wind perturbations. Open drift paths are converted to closed in the inner magnetosphere, the ring current rapidly becomes symmetric, and the entire recovery phase is produced by charge exchange loss of ring current ions. The transition between the dominance of flow-out loss in the main phase and charge exchange loss in the recovery phase occurs abruptly at $D s t_{m i n}^{*}$ in each storm.

\section{Role of Substorms}

It is clear that substorms are frequent occurrences during magnetic storms but whether they play a direct role in producing the storm-time ring current or in modifying its composition are subjects of ongoing controversy (see reviews by Kamide et al., 1998b; Gonzalez et al., 1994; Daglis and Kozyra, 2002). Central to this discussion is the difference between storm-time and isolated substorms. Major progress in this area has been made through ENA images, which revealed the spatial extent and temporal evolution of isolated compared to storm-time substorms (Reeves and Henderson, 2001). The key differences were not in the initial magnetic local time extent and intensity of the dispersionless injections but in the subsequent temporal development. The storm-time injections continue to expand eastward in MLT for many hours and intensify rather than weaken; while the isolated injections weaken to prestorm levels within an hour. The extended lifetime of the storm-time injections is associated with both quasi-steady transport (enhanced storm-time convection) and with superposed impulsive injections (implying further substorm onsets). This is consistent with earlier numerical experiments by Wolf et al. (1997) and Fok et al. (1999), which showed that a substorm dipolarization alone is not sufficient to inject ions into the inner magnetosphere; convection must remain strong during and after the dipolarization in order to bring the fresh plasma close to the Earth to enhance the ring current.

The relative importance of convection and induction electric fields in forming the ring current is still a matter of some debate. Kinetic models indicate that plasma sheet ions in the inner plasma sheet with energies below $50 \mathrm{keV}$ convect inward 
to form the bulk of the storm-time ring current (c.f., Chen et al., 1998; Liemohn and Kozyra, 2003). Substorms preferentially enhance ion populations with energies above $50 \mathrm{keV}$ (e.g., Birn et al., 1997). These ions do not convect into the low $\mathrm{L}$ shells occupied by the peak of the storm-time ring current (c.f., Wolf et al., 1997; Nose et al., 2001) but must be transported there by either induction electric fields or diffusive transport in fluctuating electric fields. If convection dominates the transport of storm-time injections, then enhancements in this high-energy population should appear as bursts of ENA that remain at large radial distances and are lost at the dayside magnetopause after one pass ( $\sim 2$ hours long) through the inner magnetosphere. These enhancements would produce only small temporary enhancements in Dst and not contribute much to the growth of the ring current.

The separate question of whether substorms are responsible for the enhancement in ring current oxygen seen during large magnetic storms is also the subject of continuing debate. While the oxygen content of the ring current increases with magnetic and solar activity (c.f. Hamilton et al., 1988; Pulkkinen et al., 2001), it has not yet been established whether this is due to rapid extraction of ionospheric ions along auroral field lines (c.f., Daglis and Axford, 1996), to mass-dependent energization of a pre-existing background population during substorm dipolarization (c.f., Grande et al., 1999), or to the enhanced stormtime convection itself. Enhanced convection extracts ionospheric ions at $\mathrm{eV}$ energies from the cleft ion fountain, and deposits them in the near-Earth plasma sheet at $\mathrm{keV}$ energies within 1.5-2 hours (c.f., Cladis, 1986; Delcourt et al., 1994; Chappell et al., 2000). This same convection may be the source of further mass-dependent energization through Speiser motion in thin magnetotail current sheets, increasing the ratio of $\mathrm{O}^{+}$to $\mathrm{H}^{+}$ energy density as the ions move into the ring current region (Nose et al., 2001).

\section{Conclusions}

Comprehensive models, multi-satellite observations, and global ENA images have fueled a new understanding of ring current energy input and decay processes. During intervals of strong storm-time convection, plasma sheet particles move deep into the inner magnetosphere on open drift paths, making one pass before being lost at the dayside magnetopause. As the convection field weakens, these ions are trapped at low $L$ values to form the storm-time symmetric ring current. Major issues in ring current build-up revolve around the relative roles of convection and induction electric fields on ring current energy input, modifications in the injection due to shielding and penetration electric fields, the role of plasma sheet density and temperature variations in modulating the energy input, the contribution of direct ionospheric injection, and the impact of the saturation of the polar cap potential in limiting the energy input during extreme events. There are two major ring current loss processes: 'flow-out' loss and charge-exchange collisions. During flow-out loss, plasma sheet dynamics are coupled to ring current evolution through the 
existence of a significant percentage of ions moving along open drift paths from the magnetotail into the inner magnetosphere. Major issues related to ring current decay processes include: the relative importance of charge-exchange and flow-out losses during the recovery phase of a variety of storms, processes that cause twophase decay, the relationship of solar wind drivers to the decay, the details of ring current trapping in response to a decreasing solar wind southward IMF Bz, and the impact of high $\mathrm{O}^{+}$content on the time-scales for loss. Other losses (Coulomb collisions and wave-particle interactions) contribute only a small ( $\sim$ few percent) amount of the decay but are extremely important to thermal plasma dynamics. Potential new loss processes in the literature are associated with the interchange instability (Sazykin et al., 2002), magnetopause compressions (c.f., Kozyra et al., 1998b), and scattering of ions in stretched magnetic fields (c.f., Anderson et al., 1997).

ENA imaging, because of its global perspective and ability to separate temporal and spatial variability has great potential for addressing some of the major unanswered questions in ring current and magnetic storm dynamics. So far ENA imaging has: (1) documented the transition from fast flow-out losses to slower charge-exchange losses during a two-phase ring current decay (Jorgensen et al., 2001), (2) confirmed the close relationship between ring current energy and the Dst variation during magnetic storms (Jorgensen et al., 1997, 2001), (3) provided a graphic demonstration of the differences between stormtime and isolated substorm injections (Reeves and Henderson, 2001), (4) captured the rapid transition between asymmetric and symmetric ring currents (open to closed drift paths) during step-function decreases in the solar wind electric field (C:son Brandt et al., 2001), and (5) identified unanticipated impacts of distorted storm-time electric field potentials on the ring current configuration in the inner magnetosphere (Fok et al., this issue). However, a whole range of important issues remain. ENA snapshots have the potential for determining the ring current composition and its variation in space and time during changing magnetic and solar activity in a way unattainable by extrapolating information from in situ observations. They provide a direct measure the ring current total energy in contrast to the Dst index that remains controversial due to its possible contamination by other current systems. The comparison between the two is key to resolving this long-standing controversy. ENA observations can go further than Dst to provide information on speciesdependent contributions to the total ring current energy and their relationships to solar drivers. Global ring current properties derived from ENA measurements are crucial to investigating a number of important issues, including: (1) the inner magnetosphere response to different types of solar drivers and to complex series of drivers, (2) the proportion of total solar wind energy that enters the ring current and inner magnetopsheric populations, (3) the response of the ring current during polar cap saturation and the implications for geoeffectiveness of extreme solar wind drivers. On the other hand, imaging ring current development simultaneously with inner plasma sheet variations and substorm injections will provide the framework 
within which to investigate the coupling between ring current and plasma sheet dynamics and between storms and substorms. Finally, simultaneous views of the near-Earth plasma sheet and ionospheric outflows in ENA and of the entire auroral oval in UV emissions will provide important insights into the relationship between substorm activity, ionospheric outflows and composition changes in the inner magnetospheric plasma.

\section{Acknowledgements}

This study was supported by the National Science Foundation under grant ATM0090165 and by the National Aeronautics and Space Administration under grants NAG5-10297 and NAG-10850. It is based on an invited tutorial presentation by J. U. Kozyra at the Magnetospheric Imaging Workshop held in Yosemite National Park, February 5-8, 2002. The authors would like to thank all of their data providers who make the ring current simulations possible, especially M. F. Thomsen, J. E. Borovsky, and G. D. Reeves at the Los Alamos National Laboratory, F. Rich at the Air Force Research Laboratory in Hanscom, MA, A. J. Ridley and G. Lu for the supplying the cross polar cap potentials used in these simulation runs, the Kyoto World Data Center for the Dst index, and CDAWeb for allowing access to the plasma and magnetic field data of the Wind and ACE spacecraft.

\section{References}

Akasofu, S.-I.: 1981, 'Energy coupling between the solar wind and the magnetosphere', Space Sci. Rev. 28, p. 121.

Alexeev, I.I., Belenkaya, E.S., Kalegaev, V.V., Feldstein, Y.I. and Grafe, A.: 1996, 'Magnetic storms and magnetotail currents', J. Geophys. Res. 101, 7737-7747.

Anderson, B.J., Decker, R.B., Paschalidis, N.P. and Sarris, T.: 1997, 'Onset of nonadiabatic particle motion in the near-Earth magnetotail', J. Geophys. Res. 102, p. 17,553.

Anderson, P.C., Carpenter, D.L., Tsuruda, K., Mukai, T. and Rich, F.J.: 2001, 'Multisatellite observations of rapid subauroral ion drifts (SAID)', J. Geophys. Res. 106, p. 29,585.

Bame, S.J. et al.: 1993, 'Magnetospheric plasma analyzer for spacecraft with constrained resources', Rev. Sci. Instrum. 64, p. 1026.

Belian, R.D., Gisler, G.R., Cayton, T. and Christensen, R.: 1992, 'High-Z energetic particles at geosynchronous orbit during the great solar proton event series of October 1989', J. Geophys. Res. 97, p. $16,897$.

Birn, J., Thomsen, M.F., Borovsky, J.E., Reeves, G.D., McComas, D.J. and Belian, R.D.: 1997, 'Characteristic plasma properties during dispersionless substorm injections at geosynchronous orbit', J. Geophys. Res. 102, p. 2309.

Borovsky, J.E., Thomsen, M.F. and McComas, D.J.: 1997, 'The superdense plasma sheet: Plasmaspheric origin, solar wind origin, or ionospheric origin?', J. Geophys. Res. 102, p. 22,089.

Burke, W.J., Maynard, N.C., Hagan, M.P., Wolf, R.A., Wilson, G.R., Gentile, L.C., Gussenhoven, M.S., Huang, C.Y., Garner, T.W. and Rich, F.J.: 1998, 'Electrodynamics of the inner magnetosphere observed in the dusk sector by CRRES and DMSP during the magnetic storm of June 4-6, 1991', J. Geophys. Res. 103, 29,399-29,418. 
Burke, W.J., Weimer, D.R. and Maynard, N.C.: 1999, 'Geoeffective interplanetary scale sizes derived from regression analysis of polar cap potentials', J. Geophys. Res. 104, p. 9989.

Burton, R.K., McPherron, R.L. and Russell, C.T.: 1975, 'An empirical relationship between interplanetary conditions and Dst', J. Geophys. Res. 80, 4204-4214.

Campbell, W.H.: 1996, 'Geomagnetic storms, the Dst ring-current myth and lognormal distributions', J. Atmos. Terr. Phys. 58, 1171-1187.

Carovillano, R.L., and Siscoe, G.L.: 1973, 'Energy and momentum theorems in magnetospheric processes', Rev. of Geophys. Space Phys. 11, p. 289.

Chappell, C.R., Giles, B.L., Moore, T.E., Delcourt, D.C., Craven, P.D., and Chandler, M.O.: 2000, 'The adequacy of the ionospheric source in supplying magnetospheric plasma', J. Atmos. SolarTerr. Phys. 62, 421-436.

Chen, M.W., Lyons, L.R. and Schulz, M.: 1994, 'Simulations of phase space distributions of stormtime proton ring current', J. Geophys. Res. 99, p. 5745.

Chen, M.W., Roeder, J.L., Fennell, J.F., Lyons, L.R. and Schulz, M.: 1998, 'Simulations of ring current proton pitch angle distributions', J. Geophys. Res. 103, 165-179.

Chen, M.W., Lyons, L.R. and Schulz, M.: 2000, 'Stormtime ring-current formation: A comparison between single- and double-dip model storms with similar transport characteristics', J. Geophys. Res. 105, p. 27,755.

Christon, S.P., Desai, M.I., Eastman, T.E., Gloeckler, G., Kokubun, S., Lui, A.T.Y., McEntire, R.W., Roelof, E.C. and Williams, D.J.: 2000, 'Low-charge-state heavy ions upstream of Earth's bow shock and sunward flux of ionosphere $\mathrm{O}^{+}, \mathrm{N}^{+}$, and $\mathrm{O}_{2}^{+}$ions: Geotail observations', Geophys. Res. Lett. 27, 2433-2436.

Cladis, J.B.: 1986, 'Parallel acceleration and transport of ions from polar ionosphere to plasma sheet', Geophys. Res. Lett. 13, 893-896.

Craven, J.D., Frank, L.A. and Ackerson, K.L.: 1982, 'Global observations of a SAR arc', Geophys. Res. Lett. 9, 961-964.

Crooker, N.U. and Siscoe, G.L.: 1974, 'Model geomagnetic disturbance from asymmetric ring current particles', J. Geophys. Res. 79, p. 589.

C:son Brandt, P., Mitchell, D.G., Roelof, E.C. and Burch, J.L.: 2001, 'Bastille day storm: Global response of the terrestrial ring current', Solar Phys. 204, p. 377.

Daglis, I.A. and Axford, W.I.: 1996, 'Fast ionospheric response to enhanced activity in geospace: Ion feeding of the inner magnetotail', J. Geophys. Res. 101, 5047-5065.

Daglis, I.A. and Kozyra, J.U.: 2002, 'Outstanding issues of ring current dynamics', J. Atmos. SolarTerr. Phys. 64, 253-264.

Daglis, I.A., Thorne, R.M., Baumjohann, W. and Orsini, S.: 1999, 'The terrestrial ring current: origin, formation and decay', Rev. Geophys. 37, 407-438.

de Michelis, P., Daglis, I.A. and Consolini, G.: 1997, 'Average terrestrial ring current derived from AMPTE/CCE-CHEM measurements', J. Geophys. Res. 102, 14103-14111.

Delcourt, D.C., Moore, T.E. and Chappell, C.R.: 1994, 'Contribution of low-energy ionospheric protons to the plasma sheet', J. Geophys. Res. 99, p. 5681.

Dessler, A.J. and Parker, E.N.: 1959, 'Hydromagnetic theory of geomagnetic storms', J. Geophys. Res. 64, p. 2239.

Ebihara, Y. and Ejiri, M.: 1998, 'Modeling of solar wind control of the ring current buildup: a case study of the magnetic storms in April 1997', Geophys. Res. Lett. 25, 3751-3754.

Ebihara, Y. and Ejiri, M.: 2000, 'Simulation study on fundamental properties of the storm-time ring current', J. Geophys. Res. 105, p. 15,843.

Fok, M.-C., Kozyra, J.U., Nagy, A.F. and Cravens, T.E.: 1991, 'Lifetime of ring current particles due to Coulomb collisions in the plasmasphere', J. Geophys. Res. 96, 7861-7867.

Fok, M.-C., Kozyra, J.U., Nagy, A.F., Rasmussen, C.E. and Khazanov, G.V.: 1993, 'Decay of equatorial ring current ions and associated aeronomical consequences', J. Geophys. Res. 98, p. 19,381 . 
Fok, M.-C., Moore, T.E. and Delcourt, D.C.: 1999, 'Modeling of inner plasma sheet and ring current during substorms', J. Geophys. Res. 104, p. 14,557.

Fok, M.-C., Wolf, R.A., Spiro, R.W. and Moore, T.E.: 2001, 'Comprehensive computational model of the Earth's ring current', J. Geophys. Res. 106, p. 8417.

Frank, L.A.: 1970, 'Direct detection of asymmetric increases of extraterrestrial 'ring current' proton intensities in the outer radiation zone', J. Geophys. Res. 75, p. 1263.

Fu, S.Y., Wilken, B., Zong, Z.G. and Pu, Z.Y.: 2001, 'Ion composition variations in the inner magnetosphere: Individual and collective storm effects in 1991', J. Geophys. Res. 106, p. 29,683.

Garner, T.W.: 2000, 'A case study of the June 4-5, 1991 magnetic storm using the Rice Convection Model', Ph.D. thesis, Rice Univ.

Gonzalez, W.D., Joselyn, J.A., Kamide, Y., Kroehl, H.W., Rostoker, G., Tsurutani, B.T. and Vasyliunas, V.M.: 1994, 'What is a geomagnetic storm?', J. Geophys. Res. 99, p. 5771.

Grafe, A.: 1999, 'Are our ideas about Dst correct?', Ann. Geophys. 17, 1-10.

Grande, M., Perry, C.H., Hall, A., Fennell, J. and Wilken, B.: 1999, 'Statistics of substorm occurrence in storm and non-storm periods', Phys. Chem. Earth 24, p. 167.

Greenspan, M.E. and Hamilton, D.C.: 2000, 'A test of the Dessler-Parker-Sckopke relation during magnetic storms', J. Geophys. Res. 105, p. 5419.

Gussenhoven, M.S., Hardy, D.A. and Heinemann, M.: 1983, 'Systematics of the equatorward diffuse auroral boundary', J. Geophys. Res. 88, p. 5692.

Hamilton, D.C., Gloeckler, G., Ipavich, F.M., Studemann, W., Wilkey, B. and Kremser, G.: 1988, 'Ring current development during the great geomagnetic storm of February 1986', J. Geophys. Res. 93, 14343-14355.

Henderson, M.G., Reeves, G.D., Spence, H.E., Sheldon, R.B., Jorgensen, A.M., Blake, J.B. and Fennell, J.F.: 1997, 'First energetic neutral atom images from Polar', Geophys. Res. Lett. 24, p. 1167.

Jordanova, V.K., Kistler, L.M., Kozyra, J.U., Khazanov, G.V. and Nagy, A.F.: 1996, 'Collisional losses of ring current ions', J. Geophys. Res. 101, p. 111.

Jordanova, V.K., Kozyra, J.U., Nagy, A.F. and Khazanov, G.V.: 1997, 'Kinetic model of the ring current-atmosphere interactions', J. Geophys. Res. 102, p. 14,279.

Jordanova, V.K., Farrugia, C.J., Quinn, J.M., Thorne, R.M., Ogilvie, K.W., Lepping, R.P., Lu, G., Lazarus, A.J., Thomsen, M.F. and Belian, R.D.: 1998, 'Effects of wave-particle interactions on ring current evolution for January 10-11, 1997: initial results', Geophys. Res. Lett. 25, p. 2971.

Jordanova, V.K., Torbert, R.B., Thorne, R.M., Collin, H.L., Roeder, J.L. and Foster, J.C.: 1999, 'Ring current activity during the early $\mathrm{Bz}<0$ phase of the January 1997 magnetic cloud', J. Geophys. Res. 104, 24,895-24,914.

Jordanova, V.K., Kistler, L.M., Farrugia, C.J. and Torbert, R.B.: 2001, 'Effects of inner magnetospheric convection on ring current dynamics: March 10-12, 1998', J. Geophys. Res. 106, p. 29,705 .

Jorgensen, A.M., Spence, H.E., Henderson, M.G., Reeves, G.D., Sugiura, M. and Kamei, T.: 1997, 'Global energetic neutral atom (ENA) measurements and their association with the Dst index', Geophys. Res., Lett. 24, pp. 3173-3176.

Jorgensen, A.M., Henderson, M.G., Roelof, E.C., Reeves, G.D. and Spence, H.E.: 2001, 'Charge exchange contribution to the decay of the ring current, measured by energetic neutral atoms (ENAs)', J. Geophys. Res. 106, p. 1931.

Kamide, Y., Yokoyama, N., Gonzalez, W., Tsurutani, B.T., Daglis, I.A., Brekke, A. and Masuda, S.: 1998a, 'Two-step development of geomagnetic storms', J. Geophys. Res. 103, 6917-6921.

Kamide, Y., Baumjohann, W., Daglis, I.A., Gonzalez, W.D., Grande, M., Joselyn, J.A., McPherron, R.L., Phillips, J.L., Reeves, G.D., Rostoker, G., Sharma, A.S., Singer, H.J., Tsurutani, B.T. and Vasyliunas, V.M.: 1998b, 'Current understanding of magnetic storms: Storm-substorm relationships', J. Geophys. Res. 103, 17705-17728. 
Kozyra, J.U., Nagy, A.F. and Slater, D.W.: 1997a, 'The high altitude energy source for stable auroral red (SAR) arcs', Rev. Geophys. 35, p. 155.

Kozyra, J.U., Jordanova, V.K., Horne, R.B. and Thorne, R.M.: 1997b, 'Modeling of the contribution of electromagnetic ion cyclotron (EMIC) waves to stormtime ring current erosion', in B.T. Tsurutani, W.D. Gonzalez, Y. Kamide and J.K. Arballo (eds.), Magnetic Storms, Geophys. Monogr. Ser., American Geophysical Union, Washington, D. C., 98 p. 187.

Kozyra, J.U., Borovsky, J.E., Chen, M.W., Fok, M.-C. and Jordanova, V.K.: 1998a, 'Plasma sheet preconditioning, enhanced convection and ring current development', in S. Kokubun and Y. Kamide, Terra (eds.), Substorms-4, Scientific Publishing Co./Kluwer Academic Publishers, p. 755.

Kozyra, J.U., Fok, M.-C., Sanchez, E.R., Evans, D.S., Hamilton, D.C. and Nagy, A.F.: 1998b, 'The role of precipitation losses in producing the rapid early recovery phase of the great magnetic storm of February 1986', J. Geophys. Res. 103, p. 6801.

Kozyra, J.U., Liemohn, M.W., Clauer, C.R., Ridley, A.J., Thomsen, M.F., Borovsky, J.E., Roeder, J.L. and Jordanova, V.K.: 2002, 'Two-step Dst development and ring current composition changes during the 4-6 June 1991 magnetic storm', J. Geophys. Res. 107, 1224, doi: 10.1029/2001JA000023.

Langel, R.A. and Estes, R.H.: 1985, 'Large-scale, near-field magnetic fields from external sources and the corresponding induced magnetic field', J. Geophys. Res. 90, p. 2487.

Lennartsson, W. and Shelley, E.G.: 1986, 'Survey of 0.1- to 16-keV/e plasma sheet ion composition', J. Geophys. Res. 91, p. 3061.

Liemohn, M.W. and Kozyra, J.U.: 2002, 'Assessing the importance of convective and inductive electric fields in forming the stormtime ring current', in R.L. Winglee (ed.), Sixth International Conference on Substorms, Univ. Washington, Seattle, pp. 456-462.

Liemohn, M.W. and Kozyra, J.U.: 2003, 'Lognormal form of the ring current energy content', $J$. Atmos. Solar-Terr. Phys, in press.

Liemohn, M.W., Kozyra, J.U., Jordanova, V.K., Khazanov, G.V., Thomsen, M.F. and Cayton, T.E.: 1999, 'Analysis of early phase ring current recovery mechanisms during geomagnetic storms', Geophys. Res. Lett. 25, 2845-2848.

Liemohn, M.W., Kozyra, J.U., Richards, P.G., Khazanov, G.V. Buonsanto, M.J. and Jordanova, V.K.: 2000, 'Ring current heating of the thermal electrons at solar maximum', J. Geophys. Res. 105, p. 27,767 .

Liemohn, M.W., Kozyra, J.U., Thomsen, M.F., Roeder, J.L., Lu, G., Borovsky, J.E. and Cayton, T.E.: 2001a, 'Dominant role of the asymmetric ring current in producing the stormtime $D s t^{*}, J$. Geophys. Res. 106, p. 10,883.

Liemohn, M., Kozyra, J.U., Clauer, C.R. and Ridley, A.J.: 2001b, 'Computational analysis of the near-Earth magnetospheric current system', J. Geophys. Res. 106, p. 29,531.

Liemohn, M.W., Kozyra, J.U., Clauer, C.R., Khazanov, G.V. and Thomsen, M.F.: 2002a, 'Adiabatic energization in the ring current and its relation to other source and loss terms', J. Geophys. Res. 107(A4), 1045, doi: 10.1029/2001JA000243.

Liemohn, M.W., Kozyra, J.U., Hairston, M.R., Weimer, D.M., Lu, G., Ridley, A.J., Zurbuchen, T.H. and Skoug, R.M.: 2002b, 'Consequences of a saturated convection electric field on the ring current', Geophys. Res. Lett. 29(9), 1348, doi: 10.1029/2001GL014270.

Lyatsky, W.: 1999, 'A possible role of ion demagnetization in substorm generation', J. Geophys. Res. 104, p. 19,095 .

Lyons, L.R. and Schulz, M.: 1989, 'Access of energetic particles to storm time ring current through enhanced radial 'diffusion', J. Geophys. Res. 94, 5491-5496.

McIlwain, C.E.: 1986, 'A Kp dependent equatorial electric field model', Adv. Space Res. 6(3), p. 187.

McPherron, R.L.: 1997, 'The role of substorms in the generation of magnetic storms', in B.T. Tsurutani, W.D. Gonzalez, Y. Kamide and J.K. Arballo, Magnetic Storms, Geophys. Monogr., AGU, Washington, 98 pp. 131-147. 
Mitchell, D.G., Hsieh, K.C., Curtis, C.C., Hamilton, D.C., Voss, H.D., Roelof, E.C. and C:son Brandt, P.: 2001, 'Imaging two geomagnetic storms in energetic neutral atoms', Geophys. Res. Lett. 28, 1151-1154.

Moore, T.E., and Delcourt, D.C.: 1995, 'The geopause', Rev. Geophys. 33, p. 175.

Moore, T.E. et al.: 1999, 'Ionospheric mass ejection in response to a CME', Geophys. Res. Lett. 26, 2339-2342.

Nose, M., Ohtani, S., Takahashi, K., Lui, A.T.Y., McEntire, R.W., Williams, D.J., Christon, S.P. and Yumoto, K.: 2001, 'Ion composition of the near-Earth plasma sheet in storm and quiet intervals: Geotail/EPIC measurements', J. Geophys. Res. 106, p. 8391.

O'Brien, T.P. and McPherron, R.L.: 2000, 'An empirical phase space analysis of ring current dynamics: solar wind control of injection and decay', J. Geophys. Res. 105, 7707-7719.

Pollock, C.J. et al.: 2001, 'Initial Medium Energy Neutral Atom (MENA) images of Earth's magnetosphere during substorms and storm-time', Geophys. Res. Lett. 28, 1147-1150.

Posner, A., Schwadron, N.A., Zurbuchen, T.H., Kozyra, J.U., Liemohn, M.W. and Gloeckler, G.: 2002, 'Association of low-charge-state heavy ions far upstream of the Earth's bow shock with space weather', Geophys. Res. Lett. 29(7), 1099, doi: 10.1029/2001GL013449.

Pulkkinen, T.I., Ganushkina, N.Y., Baker, D.N., Turner, N.E., Fennell, J.F., Roeder, J., Fritz, T.A., Grande, M., Kellett, B. and Kettmann, G.: 2001, 'Ring current ion composition during solar minimum and rising solar activity: Polar/CAMMICE/MICS results', J. Geophys. Res. 106, 19131-19147.

Rairden, R.L., Frank, L.A. and Craven, J.D.: 1986, 'Geocoronal imaging with Dynamics Explorer', J. Geophys. Res. 91, p. 13,613.

Rasmussen, C.E., Guiter, S.M. and Thomas, S.G.: 1993, 'Two-dimensional model of the plasmasphere: refilling time constants', Planet. Space Sci. 41, 35-42.

Reeves, G.D. and Henderson, M.G.: 2001, 'The storm-substorm relationship: Ion injections in geosynchronous measurements and composite energetic neutral atom images', J. Geophys. Res. 106, 5833-5844.

Reeves, G.D. and Spence, H.E.: 2001, 'Charge exchange contribution to the decay of the ring current measured by energetic neutral atoms (ENAs)', J. Geophys. Res. 106, 1931-1937.

Reiff, P.H., Spiro, R.W. and Hill, T.W.: 1981, 'Dependence of polar cap potential drop of interplanetary parameters', J. Geophys. Res. 86, p. 7639.

Richmond, A.D. and Kamide, Y.: 1988, 'Mapping electrodynamic features of the high-latitude ionosphere from localized observations: Technique', J. Geophys. Res. 93, p. 5741.

Ridley, A.J. and Liemohn, M.W.: 2002, 'A model-derived description of the penetration electric field', J. Geophys. Res. 107(A8), 1151, doi: 10.1029/2001JA000051.

Roelof, E.C.: 1987, 'Energetic neutral atom image of storm-time ring current', Geophys. Res. Lett. 14, 652-655.

Rowland, D.E. and Wygant, J.R.: 1998, 'Dependence of the large-scale, inner magnetospheric electric field on geomagnetic activity', J. Geophys. Res. 103, p. 14,959.

Sazykin, S., Wolf, R.A., Spiro, R.W., Gombosi, T.I., DeZeeuw, D.L., and Thomsen, M.F.: 2002, 'Interchange instability in the inner magnetosphere associated with geosynchronous particle flux decreases', Geophys. Res. Lett. 29, doi: 10.1029/2001GL014416.

Sckopke, N.: 1966, 'A general relation between the energy of trapped particles and the disturbance field near the Earth', J. Geophys. Res. 71, p. 3125.

Siscoe, G.L., Erickson, G.M., Sonnerup, B.U., Maynard, N.C., Schoendorf, J.A., Siebert, K.D., Weimer, D.R., White, W.W. and Wilson, G.: 2002, 'Region 1 current-voltage relation: Test of Hill model, saturation, and dipole-strength scaling', J. Geophys. Res. 107, doi: 10.1029/2001JA000109.

Sugiura, M. and Kamei, T.: 1991, 'Equatorial Dst Index 1957-1986', IAGA Bulletin 40, ISGI, SaintMaur-des-/fosses, France. 
Takahashi, S., Iyemori, T. and Takeda, M.: 1990, 'A simulation of the storm-time ring current', Planet. Space Sci. 38, 1133-1141.

Thomsen, M.F., Borovsky, J.E., McComas, D.J. and Collier, M.R.: 1998, 'Variability of the ring current source population', Geophys. Res. Lett 25, 3481-3484.

Tsurutani, B.T. and Gonzalez, W.D.: 1997, 'The interplanetary causes of magnetic storms: A review', in B.T. Tsurutani, W.D. Gonzalez, Y. Kamide and J.K. Arballo (eds.), Magnetic Storms, Geophys. Monogr. Ser. American Geophysical Union, 98 p. 77.

Turner, N.E., Baker, D.N., Pulkkinen, T.I. and McPherron, R.L.: 2000, 'Evaluation of the tail current contribution to Dst', J. Geophys. Res. 105, p. 5431.

Weimer, D.R.: 2001, 'An improved model of ionospheric electric potentials including substorm perturbations and application to the Geospace Environment Modeling November 24, 1996 event', $J$. Geophys. Res. 106, p. 407.

Wolf, R.A., Freeman, Jr., J.W., Hausman, B.A., Spiro, R.W., Hilmer, R.V. and Lambour, R.L.: 1997, 'Modeling convection effects in magnetic storms', in B.T. Tsurutani, W.D. Gonzalez, Y. Kamide, and J.K. Arballo (eds.), Magnetic Storms, Geophys. Monogr. Ser., American Geophysical Union, 98, p. 161.

Yeh, H.-C., Foster, J.C., Rich, F.J. and Swider, W.: 1991, 'Storm-time electric field penetration observed at mid-latitude', J. Geophys. Res. 96, p. 5707.

Young, D.T., Balsiger, H. and Geiss, J.: 1982, 'Correlations of magnetospheric ion composition with geomagnetic and solar activity’, J. Geophys. Res. 87, 9077-9096. 